\section{Squamous-Cell Carcinoma of the Pancreas: Report of a Case and Review of ERCP Findings}

A 69-year-old woman was evaluated by CT scan for a pancreatic body mass. She had four-month history of midepigastric pain. The physical examination was normal, and the esophagogastroduodenoscopy was normal. Endoscopic retrograde pancreatography (ERP) demonstrated a $5 \mathrm{~mm}$ duct in the head of the pancreas, with a sharp cut-off at the genu. Injection of dye after deep cannulation revealed an irregular parenchymal acinarization pattern in the body of the pancreas. A filling defect was noted intraluminally proximal to the genu, without demonstration of an upstream duct (Figure 1). Laparotomy revealed a $5 \mathrm{~cm}$ pancreatic mass, which was encasing the superior mesenteric artery. Multiple biopsies taken from the mass revealed moderately differentiated squamous-cell carcinoma. The patient subsequently received limited port radiation of $5000 \mathrm{cGy}$ to the abdominal area. A repeat CT scan of the abdomen six months later demonstrated no change in the size of the mass. It opacified with intravenous contrast (Figure 2). She is asymptomatic at present, seven months after diagnosis.

Squamous-cell carcinoma can be differentiated from adenocarcinoma by various radiological characteristics. Opacification of the pancreas mass on CT scan with intravenous contrast, as was seen in our case, and a tumor blush on angiography, have been described previously with squamous-cell carcinoma of the pancreas $(1,2)$. These features are thought to be due to increased vascularity of the neoplasm. To date, endoscopic retrograde cholangiopancreatography findings have been reported in only two cases with this entity. A tapering or cut-off of contrast dye was noted on the pancreatogram in the two published cases, and was also seen in our case (3, 4). In addition, extravasation of contrast dye into a large irregular tumor cavity was seen in one (3). A coarse, irregular acinarization pattern without an unpstream duct, as seen in our patient, has not been described before with this neoplasm. Our patient continues to do well seven months after radiatiotherapy, despite a $4.8 \%$ oneyear survival rate associated with this neoplasm.

\section{G. Koduri, T. J. Ravi}

Department of Medicine, Division of Gastroenterology

Allegheny General Hospital, Allegheny Campus

Medical College of Pennsylvania

320 East North Avenue

Pittsburgh, PA 15212-4772

USA

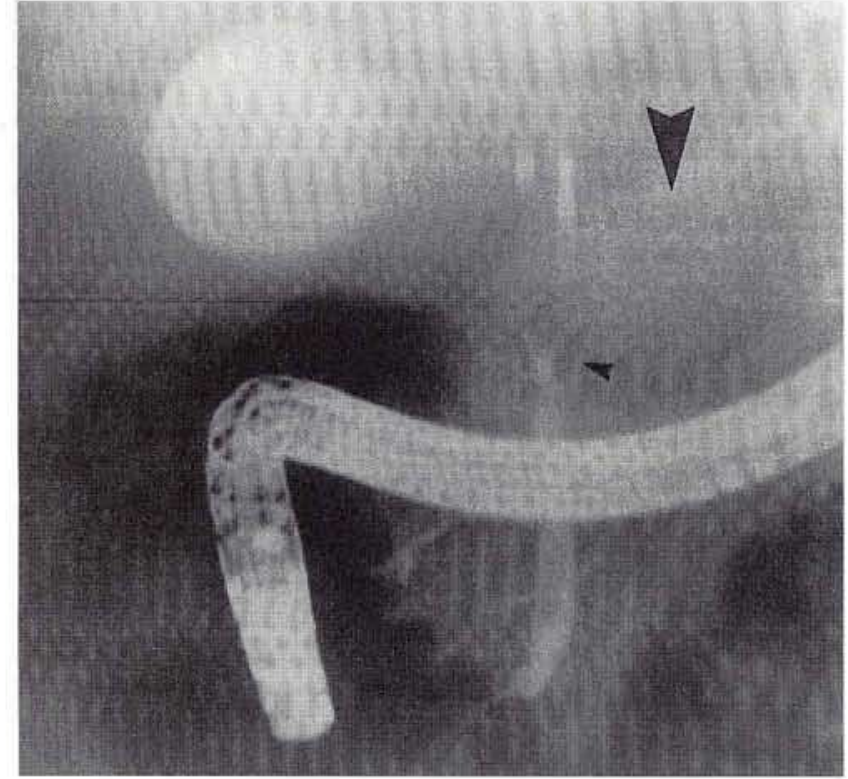

Figure 1: A filling defect in the pancreas can be seen intraluminally (small arrowhead), with an irregular acinarization pattern (large arrowhead), after deep cannulation.

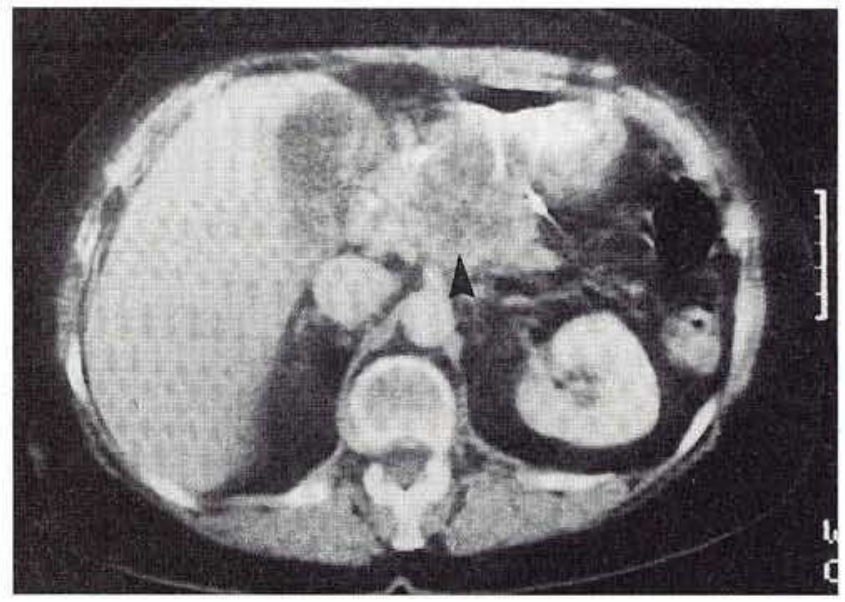

Figure 2: CT scan of the abdomen, with intravenous contrast revealing rim opacification of the pancreatic mass (large arrowhead). 


\section{References}

1. Sprayregen S, Schoenbaum SW, Messinger NH: Angiographic features of squamous-cell carcinoma of the pancreas. J. Can. Assoc. Radiol. 1975; 26: 122-124.

2. Fajardo LL, Yoshino MT, Chernin MM: Computed tomography findings in squamous-cell carcinoma of the pancreas.CT J. Comput. Tomogr. 1988; 12: 138-139.

3. Beyer $K L$, Marshall JB, Metzler $M H$, et al.: Squamous-cell carcinoma of the pancreas: report of an unusual case and review of the literature. Dig. Dis. Sci. 1992; 37 (2): 312-318.
4. Morgan J, Amazon K, Termin L: Squamous-cell carcinoma infiltrating a pancreatic pseudocyst. South Med. J. 1989; 82: 1161-1164.

\section{Acknowledgement}

We should like to thank Alice L. Pittrell for her assistance in preparing this manuscript. 